\title{
Performance testing of geogrid-stabilised ballast and sub-ballast subjected to high speed rail forces
}

\author{
Z. Yu, D.P. Connolly \& P.K. Woodward \\ Heriot Watt University, Edinburgh, UK \\ M. Horton \& T.L.H. Oliver \\ Tensar International Ltd., Blackburn, UK
}

\begin{abstract}
When high speed trains travel close to the wave propagation velocity of the supporting track-ground system, large amplitude track vibrations are generated, known as the 'critical velocity' effect - a concern on high speed lines across the world. Geogrids offer increased confinement and stability for railway subgrade materials thus increasing track performance; however benefits at critical speeds are uncertain. At critical speed, railway lines are subject to increases in both vertical and horizontal stress levels, thus causing rapid track deterioration. The ability of geogrids to reduce this deterioration is challenging to examine because testing requires that subgrade-geogrid samples are subject to rapid principal stress rotation.

A cutting edge 'true triaxial'; testing facility (GeoTT) has been developed at Heriot Watt University with 6 independent hydraulic rams that can subject a test sample (i.e. railway subgrade) to forces in all 6 directions, mimicking the principal stress rotation. The 6 rams are programmed based upon force-time histories generated by 3D finite-element models. The material properties of track materials with and without geogrid can be tested under realistic conditions for a fraction of the time and cost required for full-scale testing.

Tests have been undertaken to demonstrate the possible benefits that might be achieved using stabilised trackbed in high speed rail scenarios over a soft clay layer (using forces generated by the GeoTT rams and deformation monitored over $500 \mathrm{k}$ cycles). It is found that significant benefit can be achieved by using a hexagonal structure multi-axial geogrid with triangular apertures to stabilise the trackbed and reduce lateral and vertical movement at the sleeper level.
\end{abstract}

\section{INTRODUCTION}

\subsection{Background}

When trains travel at speeds comparable to the natural wave speed of the underlying soil, track displacements are magnified. This results in elevated stress levels within both track and soil, both horizontally and vertically, thus causing rapid track deterioration. Geogrids are commonly used on lower speed railways to increase lateral confinement between granular layers, thus improving the longevity of the track structure (Cook et al., 2015; Horton et al., 2015). This has also been shown in laboratory testing. However, the ability of geogrids to provide similar confinement for lines running at elevated critical speed ratios is unclear because testing requires rapid rotation of the principle stress direction. This paper describes research into this unknown, subjecting combined ballast, sub-ballast and subgrade materials to the tri-directional stress patterns that develop close to critical conditions.
Tests are performed using a cutting-edge testing facility at Heriot-Watt University and the effect of incorporating a stabilising geogrid is investigated.

\subsection{Literature review}

The laboratory simulation of long-term geogrid performance is a cost effective alternative to field testing. Raymond (2002); Raymond and Ismail (2003) used a compression test tank to show that ballasted track underwent reduced settlement when geosynthetically reinforced. Similarly, using a variety of different sized test boxes, McDowell and Stickley (2006), Horníček et al. (2010) and Ruiken et al. (2010) showed that geogrid reduced permanent settlement significantly.

Alternatively, Indraratna, Ngo and Rujikiatkamjorn (2011); Biabani and Indraratna (2015) used direct shear box tests to show that geogrid increases the shear strength of the ballast due to improved interlocking between geogrid and ballast. 
As confining stress was not considered in this approach, Indraratna et al. (2006, 2015); Indraratna, Nimbalkar and Christe (2009); Indraratna, $\mathrm{Ngo}$ and Rujikiatkamjorn (2012); Indraratna, Hussaini and Vinod (2013) developed a more bespoke triaxial rig to overcome this. Again, it was found that the geogrid generated additional internal confinement at the ballast/sub-ballast interface, which reduced settlement.

A challenge with this approach it is that principal stress rotation is difficult to consider, yet has been shown to have a significant effect on soil behaviour (Youd, 1972; Ansell and Brown, 1978; Chan, 1990; Lekarp, Isacsson and Dawson, 2000; Powrie, L. A. Yang and Clayton, 2007; Gräbe and Clayton, 2013). In an attempt to overcome this and more faithfully simulate the behaviour of ballasted railway track, a true triaxial test rig ('GeoTT') was developed by both Glasgow and Heriot Watt Universities. It has 6 independent hydraulic rams, thus allowing for the generation of stress patterns closer to those experienced on railway lines.

\section{LABORATORY TESTING}

\subsection{GeoTT test frame}

Four tests to investigate the performance of a hexagonal, multi-axial geogrid with triangular apertures (Tensar $\left.\operatorname{TriAx}^{\circledR}\right)$ at critical train speeds were undertaken using Heriot Watt's GeoTT apparatus. The GeoTT consists of six independent hydraulic rams, two of which were orientated in each Cartesian plane mounted in a rigid steel frame (see Figure 1).

The test sample is placed inside a bespoke steel cage with dimensions $560 \times 560 \times 560 \mathrm{~mm}$ and capable of housing large samples of track materials. The sample-holding cage has reinforced circular apertures to permit the entry of the loading rams which then impose load on the sample via an independent loading plate within the cage.

\subsection{Test set-ups}

Two main test configurations were considered in this tranche of testing:

1. Setup A: Geogrid (TriAx TX160) was installed between ballast and sub-ballast layers for one of the two tests (Figure 2). As a control, the test was repeated in the absence of geogrid to permit a direct comparison to be made in relative performance.

A reduced-scale, reinforced concrete sleeper (Figure 3) was embedded into a supporting ballast layer, which in-turn was supported by a sub-ballast layer. The concrete sleeper was

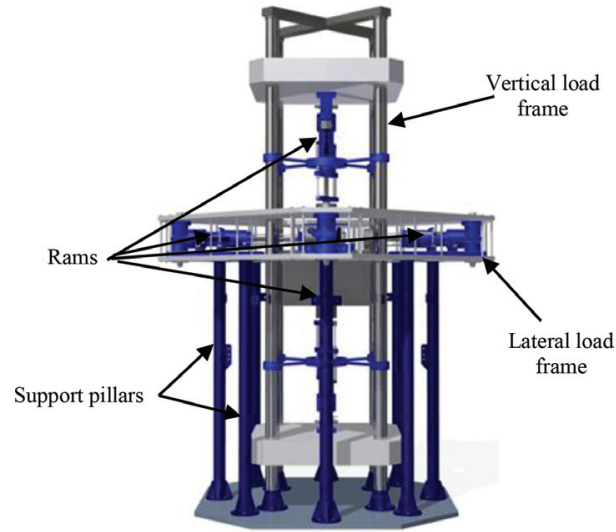

Figure 1. GeoTT Rig configuration.

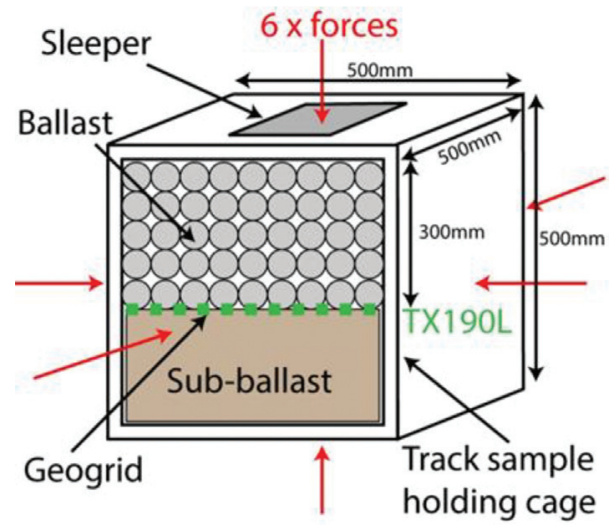

Figure 2. Test set-up A: Geogrid stabilised ballast over sub-ballast.

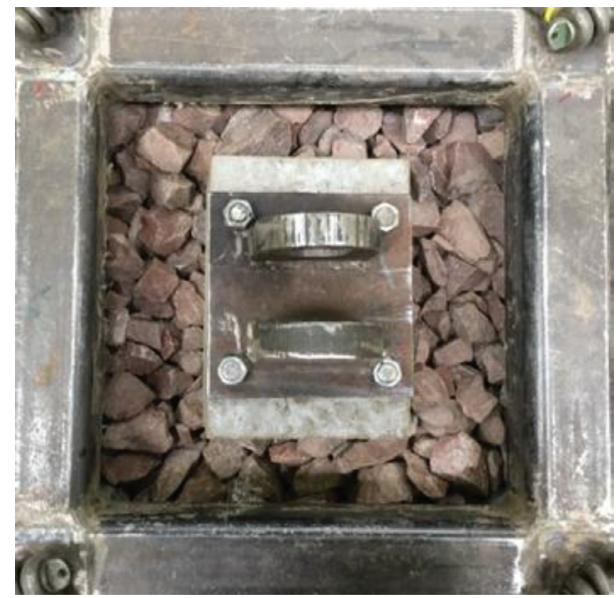

Figure 3. Test set-up A-reduced-scale sleeper (tie) on top of ballast. 


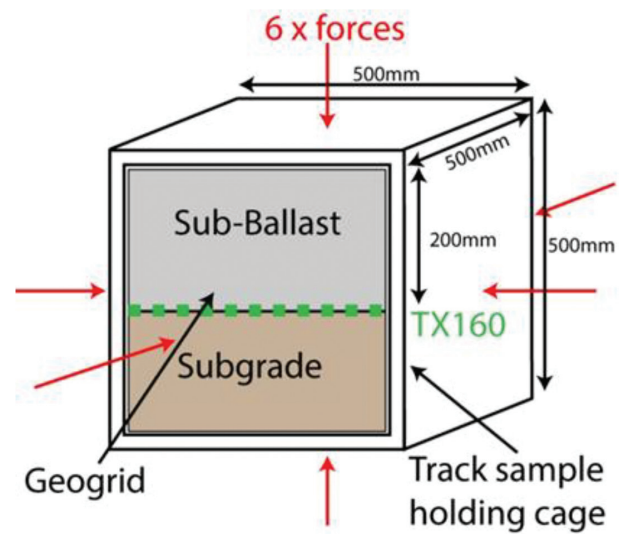

Figure 4. Test set-up B: Geogrid-stabilised sub-ballast over a soft kaolin/sand formation.

cast according to British Standards Institution, 2016. The compressive strength of concrete is class C45/55 MPa. The sleeper is trapezoidal in cross-section with $250 \mathrm{~mm}$ length and $200 \mathrm{~mm}$ width at the base.

2. Setup B: A sub-ballast layer supported by a subgrade layer. Geogrid was deployed between sub-ballast and subgrade layers for one of the two tests (Figure 4). As a control, the test was repeated in the absence of geogrid.

\subsection{Ballast}

The ballast materials used in this testing was a hard angular dolerite, commonly used on the rail network in Scotland, UK. The grading for this material (British Standards Institution, 2002) is shown in Figure 5.

All material lay within a particle range $20-63 \mathrm{~mm}$.

\subsection{Sub-ballast}

Sub-ballast material used in test setups A and B complied with $\mathrm{Cl} 603$ (Type 1 sub-base) of the UK Specification for Highway works and also consisted of a hard, angular dolerite material. The grading curve for this material [BSI 2002] is shown in Figure 6.

\subsection{Subgrade}

The subgrade used in this testing was manufactured using $80 \%$ kaolin (Imerys Polwhite E) clay and $20 \%$ sharp sand with a $9.7 \%$ moisture content (optimum moisture content (British Standards Institution, 1990 and shown in Figure 7)). This gave an approximate CBR of $3 \%$ when compacted and measured using a MEXE cone penetrometer.

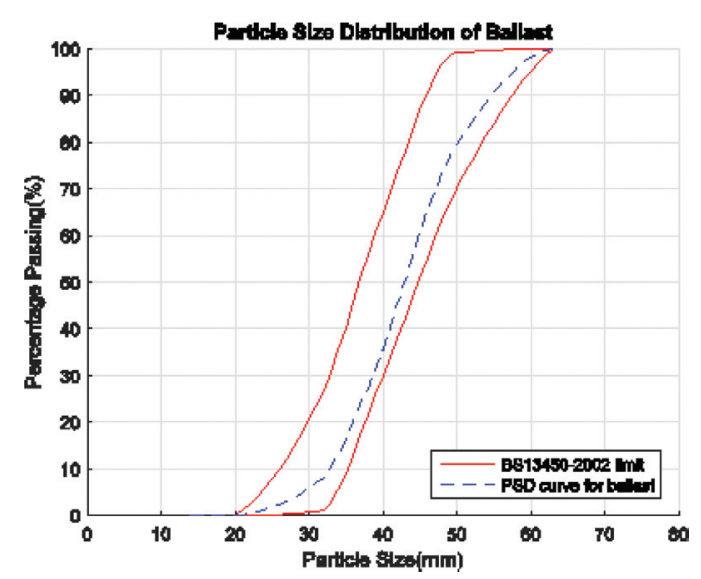

Figure 5. Particle size distribution curves for ballast used in test set A.

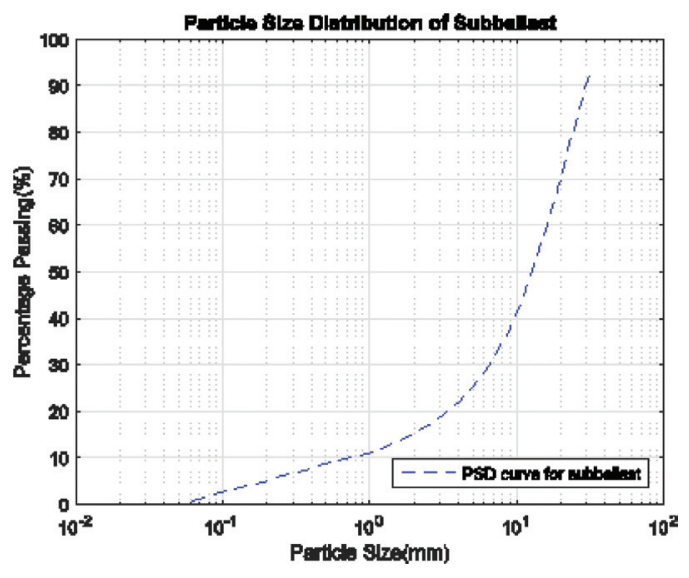

Figure 6. Particle size distribution curves for sub-ballast used in test set-up A and B.

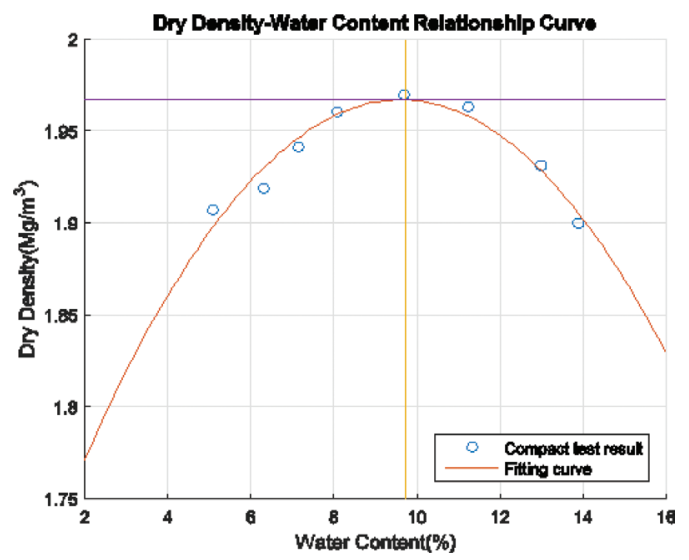

Figure 7. Dry density/moisture content curve for subgrade clay used in test set-up B. 


\subsection{Compaction}

Set-up A (Ballast/sub-ballast): Firstly, a 200mm thick layer of sub-ballast was compacted for $5 \mathrm{~min}$ utes using a vibrating plate. Once complete, $300 \mathrm{~mm}$ of ballast was placed on top and compacted.

Set-up B (Sub-ballast/subgrade): Firstly, subgrade (low $\mathrm{CBR} \approx 3 \%$ ) with a thickness of $300 \mathrm{~mm}$ was compacted in accordance with BS1377 (British Standards Institution, 1990) using a vibrating plate. Once complete, sub-ballast with height $200 \mathrm{~mm}$ was placed on top and compacted for 5 minutes to a density of $1885 \mathrm{~kg} / \mathrm{m}^{3}$.

\subsection{Geogrid}

Geogrid was used with two of the four physical tests conducted. Two types of geogrid were tested:

Tensar TriAx TX190L: This was placed between ballast- and sub-ballast for one of the set-up A tests. It is an hexagonal (120 mm pitch) structure, multiaxial geogrid with large triangular apertures (Figure 8).

Tensar TriAx TX160: This was placed between sub-ballast and soft subgrade for one of the set-up B tests. It is a hexagonal ( $80 \mathrm{~mm}$ pitch) structure, multiaxial geogrid with standard triangular apertures (Figure 9).

For each test, the selvedge edge was orientated parallel to the direction of train passage i.e. in the normal orientation for geogrid installation on a typical rail track (Figure 10).

\subsection{Test set-up}

For all testing, the mass of the steel sample cage and sample was suspended on wire ropes from the testing frame prior to applying load from the loading rams (see Figure 11).

\subsection{Computer simulations}

Computer simulations were used to generate the force-time histories that would be applied to the GeoTT hydraulic rams. Three-dimension finite element modelling was used to generate stress-time histories (based upon an 18 tonne axle load travelling at $294 \mathrm{~km} / \mathrm{h}$ ) which could then be converted to force histories. For Set-up A, the stress-time histories were calculated at the ballast/sub-ballast interface, while for Set-up B, they were calculated at the sub-ballast/subgrade interface (see below and Figure 12) as follows:

\section{Ballast/sub-ballast—Set-up A \\ Vertical direction:}

Using results from a 3D finite element model, for an 18 tonne axle load moving close to critical speed:

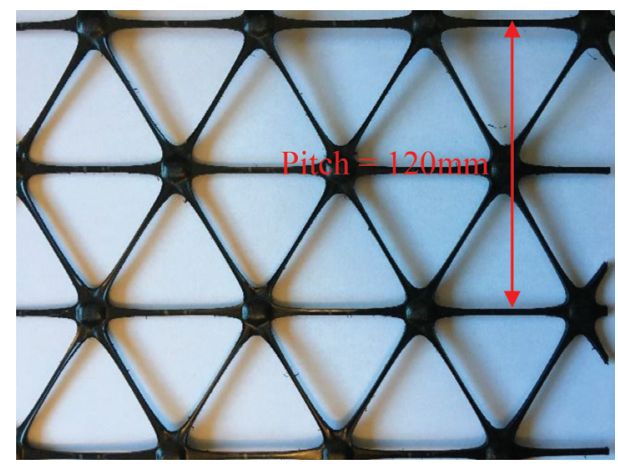

Figure 8. TX190L geogrid used in test set-up A.

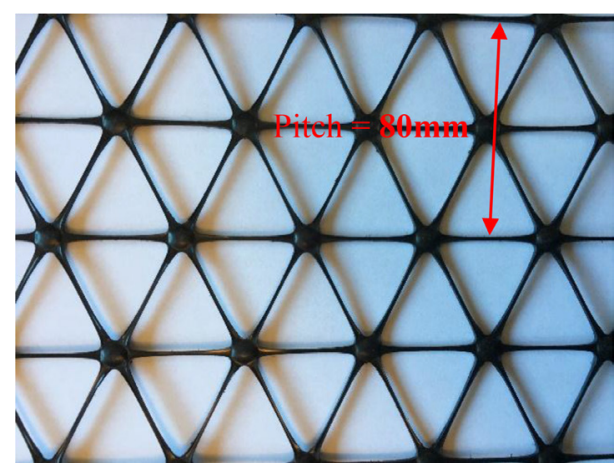

Figure 9. TX160 geogrid used in Test Set-up B.

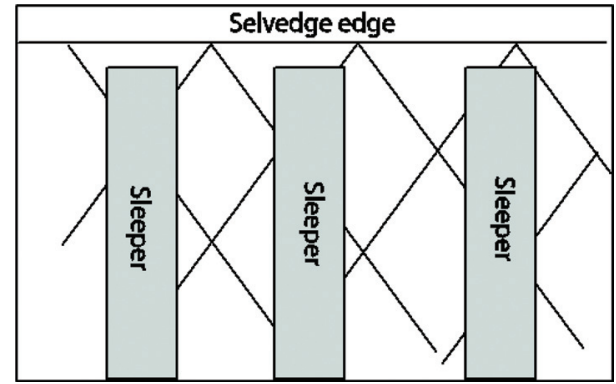

Figure 10. Selvedge edge orientation for geogrids in setups $\mathrm{A}$ and $\mathrm{B}$.

Average maximum nodal vertical stress on sleeper surface $=275 \mathrm{kPa}$

Therefore, multiplying by sleeper area gives the total force on the full-size sleeper:

Total sleeper force $=275 \times(0.2 \times 2.4 / 2)=66 \mathrm{kN}$

Again, using results from the same 3D finite element model, $60 \%$ of total sleeper stress is carried by the reduced scale triaxial sleeper $(0.25 \mathrm{~m})$ : 


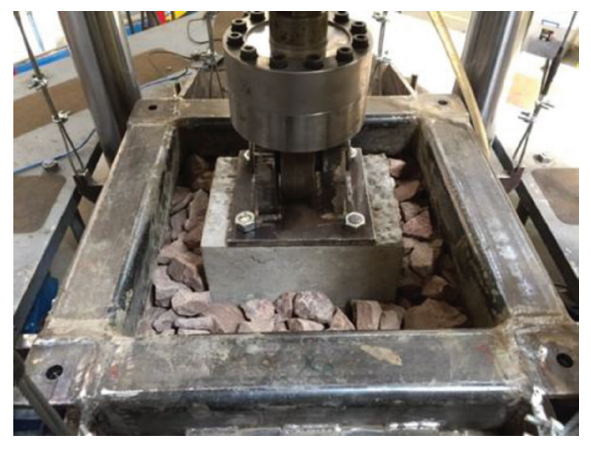

Figure 11. Final test set-up (Sample A) showing test cage suspended from testing frame by wire ropes.

Total mini-sleeper vertical force $=66 \times 0.6=39.6$ $\mathrm{kN}$

\section{Horizontal directions:}

Using the results from a 3D finite element model, the maximum horizontal nodal stresses sampled at the ballast/sub-ballast interface are:

Parallel stress $=46 \mathrm{kPa}$

Perpendicular stress $=14 \mathrm{kPa}$

Therefore, multiplying by the cage wall area gives the forces required to excite the sample in the lab:

Parallel force $=7.4 \mathrm{kN}$

Perpendicular force $=2.2 \mathrm{kN}$

Final calculations:

Finally, assuming confining stresses consistent with existing literature, the following forces were used:

Vertical force $=42 \mathrm{kN}$

Parallel force $=9.76 \mathrm{kN}$

Perpendicular force $=4.64 \mathrm{kN}$

\section{Sub-ballast/subgrade-Set-up B}

Vertical and horizontal directions

Using the results from a 3D finite element model, the mean maximum nodal stresses sampled at the subballast-subgrade interface are:

Vertical stress $=24.23 \mathrm{kPa}$

Parallel stress $=24.10 \mathrm{kPa}$

Perpendicular stress $=6.59 \mathrm{kPa}$

Therefore, multiplying by the cage wall area and accounting for confining stresses gives the forces required to excite the sample in the lab:

Vertical force $=7.08 \mathrm{kN}$

Parallel force $=7.06 \mathrm{kN}$
Table 1. Soft soil (kaolin and sand) Finite Element soil properties.

\begin{tabular}{llllll}
\hline & $\begin{array}{l}\text { Young's } \\
\text { Modulus } \\
(\mathrm{MPa})\end{array}$ & $\begin{array}{l}\text { Poisson's } \\
\text { ratio }\end{array}$ & $\begin{array}{l}\text { Density } \\
\left(\mathrm{kg} / \mathrm{m}^{3}\right)\end{array}$ & $\begin{array}{l}\text { Critical } \\
(\mathrm{km} / \mathrm{h})\end{array}$ & $\begin{array}{l}\text { Train } \\
\text { speed } \\
(\mathrm{km} / \mathrm{h})\end{array}$ \\
\hline $\begin{array}{c}\text { Soft } \\
\text { soil }\end{array}$ & 46 & 0.35 & 2000 & 310 & 294.5 \\
\hline
\end{tabular}

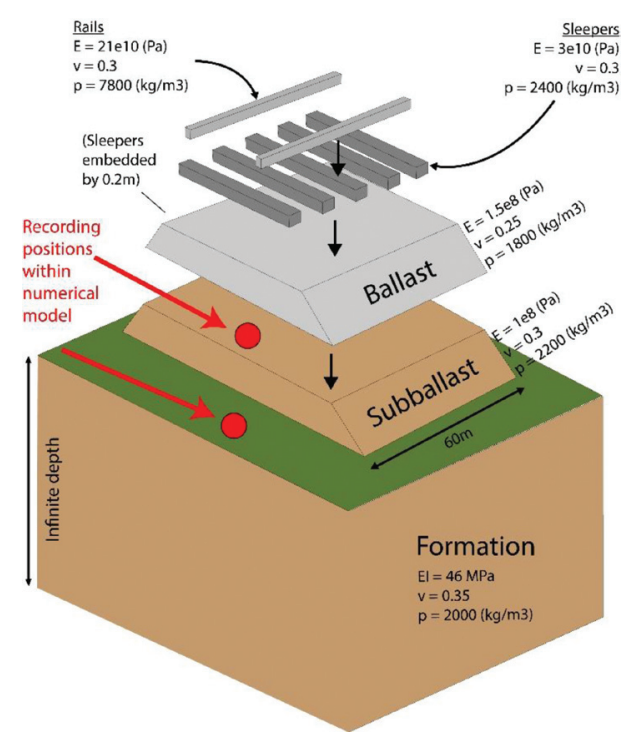

Figure 12. Recording positions for horizontal forces and soil numerical properties.

Perpendicular force $=4.25 \mathrm{kN}$

The soil numerical modelling properties are shown in Table 1 and Figure 12, and were chosen to simulate the passage of a high-speed train moving at $300 \mathrm{~km} / \mathrm{h}$ over a soft subgrade (at $93 \%$ of the critical velocity). Track properties and general model configuration are shown in Figure 12.

The following notation was used for the three Cartesian directions:

$\mathrm{X}=$ direction parallel to the direction of train passage

$\mathrm{Y}=$ direction perpendicular to the direction of train passage

$\mathrm{Z}=$ vertical

\section{RESULTS}

\subsection{Settlement response-general}

The settlement response of test Set-ups A and B is shown in Figure 13 and Figure 14 respectively. 


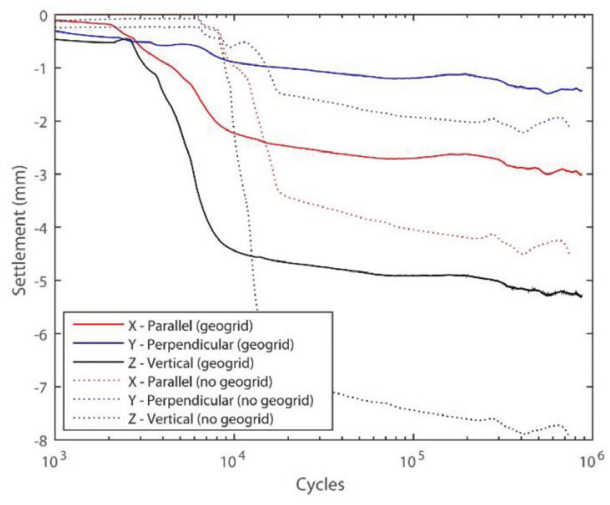

Figure 13. Set-up A-Ballast/sub-ballast settlement.

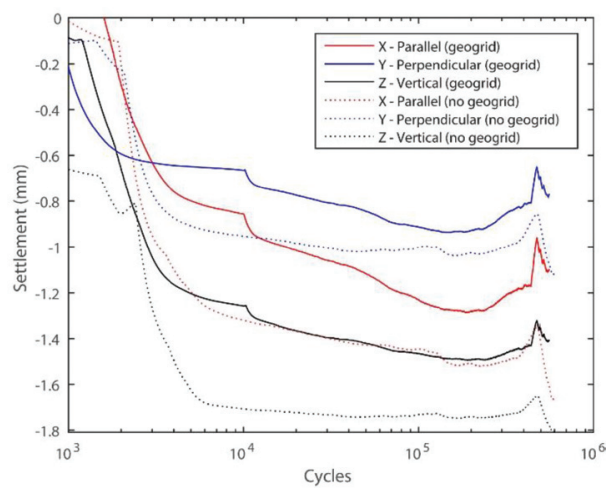

Figure 14. Set-up B-Sub-ballast/subgrade settlement.

\subsection{Setup A-Ballast/sub-ballast settlement response}

It was found that:

1. The vertical direction exhibited the largest settlement, and the direction perpendicular to the track exhibited the lowest settlement in both geogrid stabilised and non-stabilised tests.

2. Settlements were in the order of $1-5 \mathrm{~mm}$ when geogrid was present, and $2-8 \mathrm{~mm}$ when it was not.

3. The geogrid results showed a marked improvement in performance. The average improvement was $32,33,34 \%$ in the $\mathrm{X}, \mathrm{Y}$ and $\mathrm{Z}$ directions respectively (Table 4). When the geogrid was present, initial settlement occurred more quickly than when it was not used. It is possible that this effect is caused by the ballast not being fully interlocked with the geogrid during the initial cycles of testing in this test set up.
Table 2. Average \% settlement improvement of geogrid stabilised tests over unstabilised tests.

\begin{tabular}{lll}
\hline & $\begin{array}{l}\text { Sample a } \\
\text { (ballast/ } \\
\text { sub-ballast) }\end{array}$ & $\begin{array}{l}\text { Sample b } \\
\text { (sub-ballast/ } \\
\text { subgrade }\end{array}$ \\
\hline X-direction (parallel) & 33.26 & 18.11 \\
Y-direction (perpendicular) & 32.09 & 12.69 \\
Z-direction (perpendicular) & 33.60 & 15.51 \\
\hline
\end{tabular}

\subsection{Set-up B Sub-ballast/subgrade settlement response}

For Set-up B (sub-ballast/subgrade), it was found that:

1. The vertical direction exhibited the largest settlement, and the direction perpendicular to the track exhibited the lowest in both geogrid stabilised and non-stabilised tests

2. Settlements were in the order of $0.9-1.5 \mathrm{~mm}$ when geogrid was present, and $1-1.7 \mathrm{~mm}$ when it was not.

3. The geogrid results showed a marked improvement in performance. The average improvement was $18,13,16 \%$ in the $\mathrm{X}, \mathrm{Y}$ and $\mathrm{Z}$ directions respectively (Table 2)

4. Dilation occurred after approximately $4.5 \times 10^{5}$ cycles. This was most likely because the subgrade was formed from a sandy-clay mix with dilation occurring at this level.

In addition, comparing set-ups A and B, the following observations were made:

1. Settlement improvement was greater for Set-up A (ballast/sub-ballast) when geogrid was included.

2. Initial settlement was faster for Set-up B. (subballast/subgrade) compared to Set-up B.

3. Overall settlement was lower for Set-up B than Set-up A but is to be expected as the forces exerted on this sample were lower.

Average percentage settlement improvement over $500 \mathrm{k}$ cycles are shown in Table 2.

\section{CONCLUSIONS}

This paper describes a series of experimental tests to determine the potential of TriAx hexagonal structure geogrids with triangular apertures to stabilise ballasted railway lines operating at close to critical velocity. Firstly, numerical simulations were performed to characterise the stress levels obtained in track at elevated train speeds. These stress levels were then used to excite track samples, placed inside a novel true-triaxial testing rig at Heriot Watt Uni- 
versity for $500 \mathrm{k}$ cycles. Two types of track sample were tested: ballast/sub-ballast (using TX190L geogrid) and sub-ballast/subgrade (using TX160 geogrid). It was found that the TX190L geogridstabilised ballast offered a settlement improvement of approximately $33 \%$ in all 3 translational directions. Similarly, the TX160 geogrid-stabilised sub-ballast offered between $12-18 \%$ improvement depending on translational direction. In addition, it was noted that there was no visible damage to the geogrids in either test where they were included over the $500 \mathrm{k}$ cycles imposed.

Therefore, it can be concluded that the hexagonal geogrid stabilisation offers significant settlement benefits in the presence of elevated stresses typically associated with critical speed train passages over unstabilised ballast and sub-ballast.

\section{REFERENCES}

Ansell, P. and Brown, S. F. (1978) 'A cyclic simple shear apparatus for dry granular materials', ASTM Geotechnical Testing Journal, 1(2).

Biabani, M. and Indraratna, B. (2015) 'An evaluation of the interface behaviour of rail subballast stabilised with geogrids and geomembranes', Geotextiles and Geomembranes.

British Standards Institution (1990) 'Methods of test for soils for civil engineering purposes. Compactionrelated tests', $B S$ 1377-4:1990.

British Standards Institution (2002) 'Aggregates for railway ballast', $B S E N 13450$ (2002).

British Standards Institution (2016) 'Railway applications-Track-Concrete sleepers and bearers-Part 1: General requirements', $B S$ 13230-1, 2016.

Chan, F.W.K. (1990) Permanent deformation resistance of granular layers in pavements. University of Nottingham.

Cook, J., Horton, M., Roe, T. and Hornicek, L. (2015) 'Improved Trackbed Performance over low strength for-mation soils using mechanically stabilised layers', in SAIC Railway and Harbour Division ConferenceBuilding on our Infrastructure Heritage. University of Pretoria, SA.

Gräbe, P. J. and Clayton, C. R. I. (2013) 'Effects of principal stress rotation on resilient behavior in rail track foundations', Journal of geotechnical and geoenvironmental Engineering.

Horníček, L., Tyc, P. and Lidmila, M. (2010) 'An investigation of the effect of under-ballast reinforcing geogrids in laboratory and operating conditions', Proceedings of the Institution of Mechanical Engineers, Part F: Journal of Rail and Rapid Transit, 224(4), pp. 269-277.

Horton, M., Cook, J., Belyaev, V. and Ashpiz, E. (2015) 'Comparative full-Scale cyclic loading Trials on Track Bed with and without geogrid stabilisation', in Rail Engineering 2015. Edinburgh.

Indraratna, B., Asce, F., Biabani, M. M. and Nimbalkar, S. (2015) 'Behavior of Geocell-Reinforced Subballast
Subjected to Cyclic Loading in Plane-Strain Condition', Journal of Geotechnical and Geoenvironmental Engineering, 141(1), p. 4014081. doi: 10.1061/(ASCE) GT.1943-5606.0001199.

Indraratna, B., Hussaini, S. K. K. and Vinod, J. S. (2013) 'The lateral displacement response of geogrid-reinforced ballast under cyclic loading', Geotextiles and Geomembranes, 39, pp. 20-29.

Indraratna, B., Khabbaz, H., Salim, W. and Christie, D. (2006) 'Geotechnical properties of ballast and the role of geosynthetics in rail track stabilisation', Journal of Ground Improvement, 10(3), pp. 91-102. doi: 10.1680/ grim.2006.10.3.91.

Indraratna, B., Ngo, N. T. and Rujikiatkamjorn, C. (2011) 'Behavior of geogrid-reinforced ballast under various levels of fouling', Geotextiles and Geomembranes, 29(3), pp. 313-322.

Indraratna, B., Ngo, N. T. and Rujikiatkamjorn, C. (2012) 'Deformation of coal fouled ballast stabilized with geogrid under cyclic load', Journal of geotechnical and geoenvironmental Engineering, 139(8), pp. $1275-1289$

Indraratna, B., Nimbalkar, S. and Christe, D. (2009) 'The performance of rail track incorporating the effects of ballast breakage, confining pressure and geosynthetic reinforcement', in 8th International Conference on the Bearing Capacity of Roads, Railways, and Airfields, pp. 5-24. doi: 10.1201/9780203865286.ch2.

Lekarp, F., Isacsson, U. and Dawson, A. (2000) 'State of the art. I: Resilient response of unbound aggregates', Journal of Transportation Engineering, 126(1), pp. 66-75.

McDowell, G. and Stickley, P. (2006) 'Performance of geogrid-reinforced ballast', Ground Engineering.

Powrie, W., Yang, L. A. and Clayton, C. R. I. (2007) 'Stress changes in the ground below ballasted railway track during train passage', Proceedings of the Institution of Mechanical Engineers, Part F: Journal of Rail and Rapid Transit, 221(2), pp. 247-262.

Powrie, W., Yang, L. and Clayton, C. (2007) 'Stress changes in the ground below ballasted railway track during train passage', Proceedings of the Institution of Mechanical Engineers, Part F: Journal of Rail and Rapid Transit, 221(2), pp. 247-262. doi: 10.1243/0954409JRRT95.

Raymond, G. and Ismail, I. (2003) 'The effects of geogrid reinforcement on unbound aggregates', Geotextiles and Geomembranes, 21(6), pp. 355-380. doi: 10.1016/ S0266-1144(03)00044-X.

Raymond, G. P. (2002) 'Reinforced ballast behaviour subjected to repeated load', Geotextiles and Geomembranes, 20(1), pp. 39-61. doi: 10.1016/ S0266-1144(01)00024-3.

Ruiken, A., Ziegler, M., Vollmert, L. and Duzic, I. (2010) 'Recent findings about the confining effect of geogrids from large scale laboratory testing', in 9th International Conference on Geosynthetics. Brazil, pp. 3-6.

Youd, T. L. (1972) 'Compaction of sands by repeated shear straining', Journal of the Soil Mechanics and Foundations Division, 98(7), pp. 709-725. 